\title{
ADOLESCENTS' VIEWS ON CELEBRITY WORSHIP: A QUALITATIVE STUDY
}

\begin{abstract}
A phenomenological study was conducted to explore the experiences of celebrity worshipers in Malaysia in order to identify the factors motivating celebrity worship, the meanings and impact gained from the worship experience. A purposive sample of 15 adolescents who identified themselves as celebrity worshipers, were interviewed. Thematic analysis revealed that 3 major factors influenced participants to become celebrity worshipers: celebrity products, personal characteristics of the celebrity, and peer influence. Also, the themes that emerged that described participants' perceived impact of celebrity worship included emotional impact, development of strong self-determination and cultural awareness, and the enhancement of personal and social relationships. Generally, adolescents did not think there was a negative impact of their worship experiences. The study has revealed insights into how celebrities play an important role by inspiring young generation in positive ways.
\end{abstract}

Keywords: Adolescent, Celebrity worship, Factors, Impacts, Qualitative 


\subsection{INTRODUCTION}

A 'celebrity' is defined as a person whose popularity and fame makes him/her recognized by the masses, especially in the fields of entertainment or sports (“Celebrity," 2014). The concept of 'celebrity' can be seen as an 'ever-changing performative practice' involving 'ongoing maintenance of a fan base, performed intimacy, authenticity and access, and construction of a consumable persona' (Marwick \& Boyd, 2011, pp.140). Celebrities develop and manage their fan bases through deliberate self-presentation using a variety of social media sites such as Facebook, Twitter and Instagram. From a psycho-sociological perspective, celebrities are usually presented as role models and it is a normal part of life development for people to model themselves on their favorite celebrities as part of the process of identity exploration (Ferris, 2007; Greene \& Adams-Price, 1990). However, when a person's obsession with a celebrity becomes the center focus of his or her life, dysfunction may ensue. Consequently, some people will form delusional one-sided relationships with their chosen celebrities, leading to virtual obsessions with these celebrities. (Maltby, Houran \& McCutcheon, 2003). This obsession is called celebrity worship.

It can be argued that the phenomenon of celebrity worship exists along a continuum, with one end of the range devoted to passionate fans who follow their idols avidly to the other end of the spectrum bordering on the psychopathological (Sansone \& Sansone, 2014). In a 300 sample study of celebrity worship in Malaysia, it was found that $56 \%$ of the Malaysians surveyed were generally interested to follow the news of the celebrities ("The risks," 2011). Of these, $20 \%$ of participants designated themselves as fans who followed their idols' latest news, collected their idols' merchandise and actively involved themselves in their idols' events.

Studies by McCutcheon and her colleagues present celebrity worship as a type of abnormal relationship between the fans and the celebrities which comprises addiction and over-absorption (McCutcheon, Lange, \& Houran, 2002). The research findings from these studies suggest that celebrity worship is associated with pathologized, negative and deviant traits in fans (Maltby, Houran \& McCutcheon, 2003; McCutcheon, Lange, \& Houran, 2002). For instance, a dozen of Michael Jackson's fans committed suicide after his death (Thompson, 2009). Additionally, a female fan of Hong Kong actor, Andy Lau abandoned her studies, spent every penny of her family's savings, and even sacrificed her father's life, for the sake of her dream to meet Andy Lau (Wang, 2007). Not surprisingly, Weinstein and Weinstein (2003) claimed that celebrity worship is a modern religion that can replace the traditional religions. 
Celebrity worship is a global phenomenon, and has been widely investigated. However, most studies of celebrity worship have been conducted in Western societies and predominantly using the quantitative approach. Qualitative work on participants' experiences of celebrity worship is limited. Hence, there is a gap in the literature. In this study, a phenomenological approach is used to explore the experience of celebrity worshipers in Malaysia with the aim to identify the factors that influence celebrity worship and the impact gained from this experience.

\subsection{Literature Review}

\subsection{Celebrity Worship: A Continuum}

At one end of the continuum, studies of celebrity worship have yielded benefits and positive outcomes on adolescents' well-being and healthier personalities (Park, 2008). Celebrity worship may play a role in adolescent identity formation as some adolescents form an attachment to idealized images of their celebrities, and display emulations to be such as their idols (Greene \& Adams-Price, 1990). Maltby et al. (2001) postulated that celebrity worship assisted low self-esteem adolescents to develop a sense of identity and fulfillment when they feel connected with their idols and when they receive positive statements or encouragement from their favorite celebrities.

Yano (1997) also postulated that fandom in Japan is a part of the culturally affirmed relationship where celebrities and fans mutually fulfill each other's needs. Unlike Western cultures, the attitudes and behaviors of fans towards the celebrities are said to be a form of intimate interaction that build up from empathy. Cohen (2001)'s quantitative study revealed some positive outcomes that could arise from celebrity worship: emotional empathy, cognitive empathy and sharing goals and absorption.

At the other end of the spectrum, extreme forms of celebrity worship have been associated with neuroticism traits (e.g., anxiety, depression, and somatic symptoms) and psychoticism traits (Maltby, McCutceon, Ashe, \& Houran, 2001; Maltby et al., 2003). Parasocial relationships have garnered much research attention and are referred as onesided relationships that fans developed with celebrities who are not aware of them (Rubin, Perse \& Powell, 1985). McCutcheon et al. (2002) developed on this concept of parasocial relationships and proposed the absorption-addiction model for celebrity worship. In this model, absorption is an entry level of celebrity worships whereas addiction is the highest level of celebrity worship. 


\subsection{The Celebrity Attitudes Scale (CAS)}

The extent an individual is absorbed or addicted to a celebrity can be identified in the Celebrity Attitudes Scale (McCutcheon \& Maltby, 2002). The Celebrity Attitudes Scale has a Likert style response format, extending from 1 ("strongly disagree") to 5 ("strongly agree"), and is presented in a 22 -item, 23 -item, and 34 -item version. This scale detects three domains of celebrity worship with each level comprising different attitudes and behaviors and becoming more progressively extreme (Hyman \& Sierra, 2007; Sheridan, North, Maltby, \& Gillet, 2007). Level 1 is termed as entertainment-social whereby people are attracted by the celebrity because of their perceived entertaining ability and social focus (Hyman \& Sierra, 2007). Level 2 refers to the intense personal subscale whereby respondents have intense, obsessive and compulsive feelings towards their chosen celebrities (Maltby, Houran, Lange, Ashe, \& McCutcheon, 2002; Rojek, 2012). The most extreme level is borderline-pathological where fans in this stage are identified to have delusional relationships with the celebrities and it is always marked with uncontrollable fantasies and behaviors (Griffith, Aruguete, Edman, Green, \& McCutcheon, 2013).

\subsection{Celebrity Worship and Adolescent Self Identity}

Adolescents with weaker self-identities are believed to participate more in celebrity worship (Maltby, Day, McCutcheon, Gillett, Houran \& Ashe, 2005; Ashe, \& McCutcheon, 2001; McCutcheon, 2002; Yue \& Cheung, 2000) as they are more easily influenced by others, and have a higher tendency to imitate the 'licentious' behaviors of their favorite celebrities (North \& Hargreaves, 2006). Through "Deleterious Imitation," parasocial relationships with the celebrities can help individuals to construct their ideal selves (Hyman \& Sierra, 2007; Derrick et al., 2008). However, Yue and Cheung (2013) found that in Hong Kong, celebrity worship is negatively related to identity achievement. In other words, these fans who pay attention to their favorite celebrities, but not themselves, tend to result in a state of ambiguity regarding their life goals, careers, and beliefs. Liu (2013), in a similar vein, claimed that celebrity worship leads celebrity worshipers to have lower self-esteem in a sample of Hong Kong adolescents.

\subsection{Celebrity Worship and Interpersonal Relationships}

Celebrity worship is considered as an alternative for people to develop an interpersonal relationship as the characteristics of a parasocial relationship with the celebrity is said to be similar to the peer relationship in real life (Levesque, 2012). Hence, those who have dissatisfactions in real life relationships would tend to choose this 
parasocial relationship with an unrealistic individual. It is because this relationship is deemed as a safe model for people to learn about relationships, even in terms of romantic relationships (Eagle \& Kasser 2005; Karinol, 2001). Houran, Navik and Zerrusen (2005)'s quantitative study in the United States revealed that poor interpersonal boundaries (these individuals tend to feel disconnected with their social environments despite the desire to form relationships with others), predicted the most extreme form of celebrity worship. Similarly, McCutcheon, Aruguete, Scott, \& VonWaldner (2004) found that celebrity worship is negatively correlated with solitude. Hence, celebrity worshipers actually prefer socializing with people rather than being alone.

The relationship between the celebrity worshiper and celebrity has an impact on interpersonal relationships. Studies by McCutcheon et al. (2003) revealed that celebrity worship is positively related to interpersonal skills. Loneliness and the desire to form attachments led to the worship of celebrities. As participants were shy or lacking in interpersonal skills, choosing celebrity attachments were a better choice for them as they would not be rejected. In Korea, it is found that peer relationships are the indirect influence that led to fandom behaviors of the celebrity worshipers (Kim, 2013). Levesque (2012) claimed that being a member of a fan club gave these people a sense of belonging, reducing the feeling of loneliness and fulfilling their needs for personal connections.

\subsection{Celebrity Worship and Body Image}

As celebrities tend to present themselves as role models, celebrity worshippers would model themselves on their idols, even to the extent of emulating celebrities' body images. Studies have shown that body image is positively correlated to celebrity worship (Alanzalon, 2011; Maltby et al., 2005; North \& Sheridan, 2009). Therefore, adolescents who are the intense personal type of celebrity worshipers, would tend to have negative body images and would take steps to achieve their desired body images. In a similar vein, male adolescents who identified as celebrity worshipers were found to have higher eating disorders (Aruguetam, Griffith, Edman, Green, \& McChutcheon, 2014).

\subsection{Celebrity Worship and Pathology}

Some research studies on celebrity worship have focused on the pathological side of the spectrum utilizing terms like "erotomania" and "idolatry" to describe participants (Ashe et al., 2005; Jenson, 1992; Maltby et al., 2003; Maltby et al., 2004; Maltby et al., 2005). Celebrity worship is believed to be related to poorer psychological wellbeing with celebrity worshipers described as having great difficulty in knowing their own inner core and individuality. 
In fact, it was always found to be associated with depression and anxiety for the more severe group of celebrity worshipers (Maltby et al., 2001; North et al., 2007). Nearly every hypothesis in these studies stems from the supposition that interest in celebrities is a gauge of subnormal mental health.

Scholars in England also found that intense-personal and borderline-pathological fans are positively correlated with obsessive-compulsive disorder, dissociation and fantasy proneness (Maltby et al., 2005). Other findings reveal that celebrity worship and narcissism have a positive relationship as they see themselves similar to the famous celebrities (Ashe, Maltby, \& McCutcheon, 2005). Narcissism is always deemed as the result of low selfesteem hence, this is congruent to previous studies that showed celebrity worship is related to low self-esteem.

Furthermore, Maltby et al. (2004) found that students in England who are intense personal type of celebrity worshipers are related to lower social complexity. In summary, these people display low desire to form membership in diverse groups. This contradicts previous studies which show that people who worship celebrities, do so as they desire interpersonal relationship satisfaction. Another study with participants from Europe, United States, Canada and Australia also showed similar results whereby people who are always preoccupied with celebrities were significantly correlated with dissociative experience (Sheridan, Maltby \& Gillet, 2006). The suggestion is that these celebrity worshipers would likely detach themselves from reality due to their fantasies, and hence, this leads to dissociation. Alternatively, people who are prone to fantasy and dissociation are more likely to worship celebrities in a more extreme ways (Maltby et al., 2005).

The review of the relevant literature on celebrity worship shows that in many studies, celebrity worship has been associated with negative personality traits, features and pathology. However, it is important to note that these studies focus more on the extreme forms of celebrity worship. Minor forms of celebrity worship have shown some beneficial effects, particularly in role modelling, increase in empathy and interpersonal relationships, and identity formation. However, most of the studies reviewed used primarily the quantitative approach. As a result, they do not capture the essence of what is means to be part of celebrity worship. Furthermore, there is a dearth of empirical research that explores the experiences, the meanings and the impact attached to these experiences for Malaysian adolescents. Most importantly, the contributing factors of celebrity worship are rarely mentioned in the literature. This study attempts to address the research gap by undertaking a qualitative study with adolescents who participated in celebrity worship and to explore their experiences in depth. 


\subsection{Methods}

\subsection{Approach and Research Design}

In this study, participants were purposively selected and invited to participate in a qualitative interview. The inclusion criteria for the research study were that each participant had to be an adolescent from Malaysia and were celebrity worshipers. To ensure the inclusion criterion was met, a self-reported questionnaire (Celebrity Attitudes Scale) was used (Maltby et al., 2002), This scale is a 23 -item revision of a 34-item scale originally developed by McCutcheon et al. (2002) that assesses the favorableness of a respondent's absorption or addiction to a favourite celebrity. Each item is rated on a 5-point Likert scale ranging from strongly disagree to strongly agree. The scale measures forms of celebrity worship including Entertainment-Social (10 items), Intense-Personal (9 items), and Borderline Pathological (4 items). The three subscales demonstrated good reliability and validity, and its total score has been found to correlate positively with favorableness of attitudes toward celebrities in general (McCutcheon et al., 2002). Therefore, this study used the total score instead of individual scores to define celebrity worshippers. As defined by Maltby et al. (2002), a score at or above the scale midpoints on the three subscales of the CAS is considered as a celebrity worshiper. This scale has been validated in different countries such as the United States, United Kingdom and Malaysia (Maltby et al., 2002; McCutcheon, et al., 2002; Swami et al., 2010).

The Celebrity Attitude Scale was sent to 121 English-speaking school-aged adolescents aged between 13 and 18 years $(\mathrm{M}$ age $=15.5$ years, $\mathrm{SD}=1.7)$ from central Malaysia. Of the sample of 121 , fifteen $(6$ male and 9 female $)$ school-aged adolescents who scored above scale midpoints were included in the interview session on the basis of CAS scores. More than half described their ethnic origin as Chinese $(\mathrm{N}=8)$, whilst 5 as Malay, and 2 as Indian. All respondents reported to be single.

The qualitative, one-on-one, semi-structured interviews were conducted to gain in-depth information from the participants. Phenomenology is the theoretical construct that underpins the conduct of these interviews (Husserl, 1970). Husserl (trans,1970), the founder of phenomenology suggests that the focus of this approach is to understand the participants' lived experiences in their pre-reflective condition and to revisit and re-examine those taken for granted experiences in order to expose new and forgotten meanings. In order to explore the lived experiences of the participants, the researcher had to 'bracket' all previous prejudices about celebrity worship and approach the phenomenon with new eyes (Husserl, 1970; Moustakas, 1994). 
Interviews were conducted consecutively until saturation was achieved. Fifteen interviews were conducted from May to July 2015. The interview questions were derived from a thesis titled "Kpoped!: Understanding the Filipino Teens' Consumption of Korean Popular Music and Videos" by Alanzalon (2011), which comprised the factors for participating in celebrity worship and the positive or negative impact of being a celebrity worshiper. As in a phenomenological interview, probing questions were also asked during the interviews to extract more detailed information or for clarification. In the actual study there were six male and nine female participants between the ages of 13 and 18 years $(\mathrm{M}$ age $=15.5$ years, $\mathrm{SD}=1.7)$.

\subsection{Data collection and analysis}

Participants were briefed about the purpose of the study, procedures, confidentiality of their data, risks and benefits. Based on the information given, informed consent was then gained from each participant. All interviews were audio recorded. On average, each interview lasted about 30 minutes. All data that were collected from the interviews were anonymized during the transcription process.

During analyses, a thematic phenomenology approach was used, as described by Moustakas (1994), to provide a rich description of the lived experience of celebrity worshipers in Malaysia. It is comprised of four steps: epoche, phenomenological reduction, imaginative variation, and synthesis. During the first step, equal attention was given to all differing data of participants to interpret transcripts in a more objective manner. In the second step, phenomenological reduction, a process of getting precise and meaningful research findings was applied. The researcher horizonalized significant words or phrases, created tentative labels for chunks of data (open coding), identified relationships among the open codes (axial coding), and grouped axial codes into themes. The third step, imaginative variation, involves data interpretations from different angles to discover the essence of the lived experience which were beyond the facade of the textural meaning. The last step, synthesis, involves an overall description of the essence of the lived experiences of celebrity worship among the participants. To improve the validity of the research, member checking was applied by asking the participants to check the transcripts. An audit trail of all coding and themes was maintained and there was systematic recording of self-reflexivity in the form of a log book to reduce any possible bias by the researcher (Creswell, 1998). 


\subsection{Results}

Three main themes emerged from the data to answer the factors that motivate celebrity worship and these are

presented in turn below.

\subsection{Celebrity Products}

Participants reported that they were influenced by celebrity products such as music videos and songs to become celebrity worshipers.

“I was addicted to Bruno Mars's songs, and I watch his music videos for almost everyday. I think this is why I start to like him." P12

“Once I played Big Bang song, even I stopped the song, but it can keep playing in my mind.” P5

"For me Jay Chou's music will bring positive energy to people. The world becomes better because of him. " P10

Another participant mentioned he became involved in the celebrity-obsessed culture after he saw celebrities sell their products in an advertisement.

"Oh my god. David Beckham is so hot and sexy when he wears skimpy H\&M underwear in an advertisement. I love to see him everyday." P2

\section{Personal Characteristics of Celebrities}

Another contributing factor raised by some participants was the celebrity's appearance:

"Lee Min-Ho is so handsome in ad, magazine, and drama. He always smiles at me in front of my computer" $\mathrm{P} 1$

"To me, Tyra Banks is the most beautiful model? Do you think so?" P13

Some participants were influenced by the celebrities' good singing voices or good acting:

"Justin Bieber's voice is very charming, especially when he sings 'Baby'." 4

“Gem Tang's voice is the most powerful singing voice. You should listen her famous song 'Exist.' You will surprise with her super high voice. I sure you will love her." P11

“Jay Chou can sing well and act well in his drama. I can't think a reason why I don't love him." P10 
Some participants felt appreciation from their favorite celebrities:

"I think JJ Lim very cares for his fans, no matter where do the fans come from. So this is a reason that I like him." $\mathrm{P} 9$

"This is a situation when I went to Korea, Big Bang were like very surprised, and they greeted me and even signed for me, and they keep on telling me that they will come to Malaysia. They really care about me." P5

Moreover, positive attitudes of the celebrities were emphasized by the participants as the reason for their obsession with the celebrities:

“Justin Bieber always withstands with his own style. Although some of my friends don't like him, but I love him. " P4

"Tyra Banks always know her want to do what. No matter what she wants, she will step by step to do it. One day, I wish to become her as a supermodel. " $\mathrm{P} 13$

"Their attitude is very nice. I can say that Big Bang are very humble since that time when I was exposed to them actually they are very famous in Korea." P5

\section{Peer Influence}

Some of the participants commented that peer influence could explain their source for celebrity worship:

"Actually I also think is my friends influenced me to love Lee Min-Ho. They asked me to watch his drama. Since that day, I become his big fan." P1

"I choose to be a fan of Mayday (Taiwanese band) is because of my friend's influence. All my close friends love their album. We will go to their concerts every time they came to Malaysia." P14

Four main themes emerged from the data to reveal the impact gained from the worship experience and these are presented in turn below.

\section{Emotional Impact}

Some students took the view that celebrity worship was a way of modulating their negative to positive emotions: 
"Sometimes when I feel about a little bit emotional, then I will listen to Jay Chou's songs to comfort myself." P10

"I will very sad when I miss my dad because my dad had already passed away. By watching my favorite comedian, Jerry Seinfeld's movies, it can cheer me up, yeah." P3

“When I was stressed I will listen to Gem Tang's songs. And then ...my stressed is released.” P11

“If I felt very unhappy or stressed, Stephen Chow's (Hong Kong Comedian) movies are one of the ways to make me laugh." P7

\section{Development of Strong Self-Determination}

The development of strong self-determination was a positive effect reported in a number of interviews. Some felt that the experience of worshiping celebrities have led them to become more goal-directed:

"I think Justin Bieber influenced me a lot. He works very hard, so I will follow him to work hard.” P4

“When I read Maydays' song lyrics, I tend to ask myself why I so care about others' judgment. I don't live because of others. I live on my own." P14

"One Direction (English-Irish pop boy band) are also my motivation, because one of their pop song 'Drag Me Down' made me don't want to give up when I was in the dark. Also when I did certain things, I knew I need to put more efforts, and don't give up easily no matter how the difficulties are." P15

"When I see Shila Amzah achieved great success in China because of her efforts, I believe I can be like her to achieve my dream also" $\mathrm{P} 8$

"Stephen Chow teaches me a lot. One of the things I learnt from him is never give up spirit. I will make him to become my role model. Try to do everything like what he can do." $\mathrm{P} 7$

\section{Enhancing Personal and Social Relationships}

There were some cases where participants acknowledged their personal and social relationships were enhanced as a result of being celebrity worshipers. Some felt that the experience of worshiping celebrity helped in improving their family relationships. 
"In Jay Chou's song it teaches you actually err...you need to be good to your parents because they feed you, they always beside you when you are young. But he is right, I will learn that like u need to be good to your parents no matter what happened.” $\mathrm{P} 10$

"I saw how Shila Azmah cared her parents. In a show, she even cried when her parents can't accompanied her in a competition. She made me know the importance of family support." P8

"Let's say Big Bang have come to Malaysia and held their concert, my family actually bring me to concert. In this journey I think we spent our family gathering time. And family gathering I think is quite important in maintaining a healthy family relationship and I think that improves the relationship." P5

Some of the participants focused on the positive effect of their interpersonal relationships:

"Because of Lee Min-Ho, I have improved my socializing skills, so that made me able to survive and make new friends in a new place. I can make friends very easily because we have same idol." P1

"Actually last time I used to be shy, but after I know Ze:A I start to approach more friends. I can be friend with anyone in my company easily. " P6

"Some friends who love Jay Chou's songs also right, we will more contact with each other" P10

\section{Cultural Awareness}

A number of participants commented that they were more exposed to a new culture, in this case, Korean, as celebrity worshipers:

"Learned a lot of their culture. It's pretty fun to able speak same language with my oppa (Korean term for big brother)." P1

"I will motivate me to learn a new language and culture since they are Korean boy band as learning a new language is quite important nowadays since the globalization is very trending now." P5

"Because of Ze:A I start to learn Korean language and the culture." P6

\subsection{Discussion}

A phenomenological study was conducted to investigate the experience of celebrity worshipers in Malaysia in order to identify the factors motivating celebrity worship, the meanings attached to this experience and the impact gained from the worship experience. Generally, the findings of this study provided new insights to various aspects of 
the experience on celebrity worship and validated some earlier findings reported in the literature. Qualitative data found that 3 major factors influenced participants to become celebrity worshipers: celebrity products, the personal characteristics of the celebrity, and peer influence.

While some participants expressed that celebrity products (e.g., feel impressed with the celebrities' music or performance) and personal characteristics of the celebrity (e.g., feel appreciation from the celebrities or the celebrities exhibit positive attitudes) were the contributing factors to keep their loyalty towards a celebrity, others encountered peer influence when they were first attracted to a celebrity. This concurs with the absorption-addiction model which suggests that the first level of celebrity worship is entertainment-social whereby people would be attracted to the celebrity because of these 2 factors (Hyman \& Sierra, 2007, Swami et al., 2010). Also, at this level, participants devoted much time and energy to their celebrities because of the physiological characteristics of the celebrity like good looks and good voices. This is considered a form of sensual enjoyment where people enjoy looking at their attractive appearances or listening to charming voices. Notwithstanding this, some psychological characteristics such as appreciation of the fans, good attitudes and positive energy of the celebrities can further motivate the participants to worship. Again, this is congruent with the absorption-addiction model which argues that people would pursue a parasocial relationship with a successful celebrity (Maltby et al., 2001; McCutcheon et al., 2002).Generally, the definition of a 'successful celebrity' for a celebrity worshiper is someone who cares for the fans and possesses good attitude. Next, the theme of peer influence is rarely discussed as a factor of celebrity worship in the previous literature. However, it is not surprising because peers are the most powerful socialization agent during adolescence. A literature search found that the preference and hobbies of the adolescents will more easily influence by their friends (Urberg, Degirmencioglu, \& Pilgrim, 1997).

Also, the themes that emerged describing perceived impact of celebrity worship on participants included emotional impact, development of strong self-determination, enhancement of personal and social relationships, and cultural awareness. Most interesting in the context of this research was that adolescents did not think there were any negative impact of their worship experiences. In fact, most participants were in consensus that the experience of celebrity worship brought positive emotional impact into their life. More accurately, it seems to help them to offset negative emotions, and to reduce stress in their lives. Indicatively, the creation of parasocial relationships between fans and celebrities could positively affect their moods and emotions and functions as a coping mechanism to deal 
with the stressors in their lives. This finding is incongruent with the literature which suggests that celebrity worship is related to poorer emotional wellbeing (Maltby et al., 2001; Maltby et al., 2004; North et al., 2007).

One research finding in this revealed participants' perception of celebrity worship as helping them to build their self-determination. This finding is in alignment with Rojek (2012)'s work which suggested that people would develop strong self-determination through the process of worshiping celebrity. For example, under the influence of the celebrities who are always working hard in order to achieve their dreams, the participants would model this characteristic of the celebrity and apply it into their lives. Moreover, some of the participants even mentioned that they have the desire to be the same as their favorite celebrity in terms of values, behaviors and even personalities. Also, the theory also suggested the same phenomenon where the celebrity worshipers would imitate their group member's attitudes, emotions and behaviors (McCutcheon, et al., 2002).

Is celebrity worship a way of facilitating personal and social relationships? Some participants in the research study perceived that the worship experience led to the achievement of enhanced personal and social relationships. As hypothesized in previous literature, celebrity worshipers are shy or lacking in interpersonal skills to approach others (Eagle \& Kasser 2005; Karinol, 2001; Levesque, 2012). Some of the participants did mention their deficits in socializing before worshiping the celebrities. They explained that being a celebrity worshiper could help them to make friends who share the same interests. Also, it is useful to improve their socializing skills. Levesque (2012) claimed that the sense of belonging given by members of fan clubs has helped the celebrity worshipers to feel connected to others in the same fandom. Thus, this study's finding is incongruent to Ashe and McCutcheon's (2001)'s study which suggest that people who worship celebrities tend to have more deficits in interpersonal relationships. In contrast, this study found that celebrity worship has helped the participants to gain a sense of contentment by enhancing their personal and social relationships and even improving their ability of making new friends. Additionally, some participants also mentioned their worship experience enhanced their relationships between the family members, provided that the family members are being supportive to the behaviors of the celebrity worshipers.

Other than that, most participants, if not all, reported an increase in cultural awareness as a result of their worship experiences. The findings were also supported by the results of previous literature which suggest that having a parasocial relationship with the celebrity can help one in gaining new culture and language exposure (Derrick, et al., 2008; Hyman \& Sierra, 2007; Yue \& Cheung, 2000). Indeed, most participants reported learning about the cultures of their favorite celebrities, including acquiring a new language. All these positive outcomes of celebrity worship are 
believed to indirectly improve self-esteem of the celebrity worshipers. Looking at the positive self-identity development that the celebrity worshipers believed they gained in this study, the question that needs further investigation is whether it is unhealthy for adolescents be a celebrity worshipers.

Although celebrity worship has been associated with pathological or dysfunctional issues (Houran et al., 2005; Sheridan et al., 2006), these research findings have shown the opposite outcomes based on the diverse views of the participants. The following reasons are proposed to justify the current findings. First, the adolescents in this study may be considered as participating in a mild form of celebrity worship, known as 'entertainment social' celebrity worship. Distinguished from borderline pathological celebrity worship, the current form of worship appears to be linked to positive outcomes for the adolescents (Maltby et al., 2001; McCutcheon et al., 2002). Secondly, with the advent of digital and media technologies and assiduous fan management on the part of celebrities, it is increasingly evident that adolescents would be pulled into the world of celebrity worship (Cohen, 2001; Karinol, 2001; Levesque, 2012; Marwick \& Boyd, 2011; North et al., 2007). It is getting normalized for adolescents to be attracted to the celebrities as media and technologies inundate them with celebrity images, celebrity endorsements and celebrity sightings. Third, the findings may also suggest that adolescents who are celebrity worshipers (either in mild or extreme forms), are unaware of the many underlying issues related to celebrity worship that may affect their health systems (Derick et al., 2008; Griffith et al., 2013; Houran et al., 2005). A cross-informant study hence, would provide a better understanding of the celebrity worship phenomenon among adolescents (Creswell, 1998).

However, this study offers new understanding of the root causes and outcomes of celebrity worship experience, especially from the perspectives of adolescents in Malaysia. This, in turn, raises some issues for practitioners and creates a platform for further research. For parents, guardians, teachers and counselors, these findings can provide a better understanding of the behaviors of the celebrity worshipers. Looking at the positive outcomes of being a celebrity worshiper, these parties could now have a more open mindset and acceptance towards celebrity worshipers. By giving their support, parents and teachers can have better relationships with the celebrity worshipers and understand their behaviors and activities. As a result, they can provide proper guidance to the celebrity worshipers instead of continuing with negative stereotypes of celebrity worshipers which could lead to eventual isolation of the adolescents. Moreover, since the celebrities are influential to them, parents and teachers can use positive characteristics of celebrities in guiding the celebrity worshipers. 
In terms of the limitations, the participants were screened by using the Celebrity Attitude Scale. The overall CAS scores were used to select the participants for the phenomenological interviews. CAS is capable of identifying the three different levels of celebrity worship and it is said that each level of celebrity worship is associated with different personalities and psychological impact. Hence, the differences in terms of the factors and impact of celebrity worship between celebrity worshipers from the three different levels were not investigated in this study. A future study could be conducted in this area and with a larger sample size.

Another limitation is concerned with the generalizability of the findings. A sample size of 15 adolescents in this qualitative study means that the research findings cannot be generalized. However, as an exploratory study, the findings can hold significance in terms of transferability: if readers were to see similarities in their own contexts or view the procedures of the conduct of this study as worthy of replication in their own settings, then this study would have contributed to new knowledge in this field (Hammersly, 2012).

To conclude, this study identified the factors that motivated celebrity worshipers and also investigated the impact of celebrity obsession. The interesting finding is that from the perspective of celebrity worshipers, celebrity worship could possibly do more good than harm. This is incongruent with the majority of the literature on celebrity worship. As such, a larger study using both quantitative and qualitative methods is suggested to investigate more on this phenomenon.

\section{Compliance with Ethical Standards}

Funding This study was not supported by any grant or fund.

Conflict of Interest The authors declare that they have no conflict of interest.

Ethical Approval All procedures performed in studies involving human participants were in accordance with the ethical standards of the institutional and/ or national research committee and with the 1964 Helsinki declaration and its later amendments or comparable ethical standards.

Informed Consent Informed consent was obtained from all individual participants included in the study. 


\section{References}

Alanzalon, S.M. (2011). Kpopped! Understanding the Filipino Teens' Consumption of Korean Popular Music and Videos, (Unpublished Undergraduate Thesis). University of the Philippines College of Mass Communication, Philippines.

Aruguetam, M., Griffith, J., Edman, J., Green, T., \& McChutcheon, L. (2014). Body image and celebrity worship. Implicit Religion, 17(2).

Ashe, D. D., \& McCutcheon, L. E. (2001). Shyness, loneliness, and attitude toward celebrities. Current Research in Social Psychology, 6, 124-133.

Ashe, D. D., Maltby, J., \& McCutcheon, L. E. (2005). Are celebrity-worshippers more prone to narcissism? A brief report. North American Journal of Psychology, 7, 239-246.

Celebrity. (2014). Retrieved from http://www.oxforddictionaries.com/definition/english/celebrity

Cohen, J. (2001). Defining identification: A theoretical look at the identification of audiences with media charaacters. Mass Communication and Society, 4(3), 245-264.

Creswell, J. (1998). Qualitative inquiry and research design: Choosing among five traditions. Thousand Oaks, CA: Sage.

Derrick, J. L., Gabriel, S., \& Tippin, B. (2008). Parasocial relationships and self discrepancies: Faux relationships have benefits for low self-esteem individuals. Personal Relationships, 15(2), 261-280. doi:10.1111/j.14756811.2008.00197.x

Eagle, Y. \& Kasser, T. (2005). Why do adolescent girls idolize male celebrities?. Journal of Adolescent Research, $20,263-283$.

Ferris, K. (2007). The sociology of celebrity. Sociology Compass, 1(1), 371-384.

Greene, A.L. \& Adams-Price, C. (1990). Adolescents' secondary attachments to celebrity figures. Sex Roles, 23(7/8), 335-347.

Griffith, J., Aruguete, M., Edman, J., Green, T., \& McCutcheon, L. (2013). The temporal stability of the tendency to worship celebrities. SAGE Open, 3, 1-5. doi: 10.1177/2158244013494221

Hammersley, M. (2012). Methodological paradigms in educational research. British Educational Research Association On-line Resource, September 2012, 1-30. Available at: http://www.bera.ac.uk/resources/methodological-paradigms-educational-research. 
Houran, J., Navik, S., \& Zerrusen, K. (2005). Boundary functioning in celebrity worshippers. Personality and Individual Differences, 38, 237-248.

Husserl, E. (1970). Logical Investigations, Vol I \& II, (trans J.N. Findlay). New York, Humanities Press. (Original work published 1900).

Hyman, M.R. \& Sierra, J.J. (2007). Idolizing sports celebrities: A gateway to psychopathology? Young Consumer, 11(3), 226-238.

Jenson, J. (1992). Fandom as Pathology: The Consequences of Characterization. In L. Lewis (Ed.), The Adoring Audience (pp. 9-29). London.

Karinol, R. (2001). Adolescent females' idolization of male media stars as a transition into sexuality. Sex Roles, 44, $61-77$.

Kim, S. S. (2013). An influence on adolescents' fandom activities. The Journal of the Korea Contents Association, 13(6), 167-176.

Levesque, R. J. R. (2012). Idols and idolization. In R.J.R. Levesque, Encyclopedia of Adolescence, Volume 1 (pp. 1377-1378). New York, NY: Springer Science \& Business Media.

Liu, J.K.K. (2013). Idol worship, religiosity, and self-esteem among university and secondary students in Hong Kong. Discovery - SS Student E-journal, 2, 15-28.

Maltby, J., Day, L., McCutcheon, L. E., Gillett, R., Houran, J., \& Ashe, D. D. (2004). Personality and coping: A context for examining celebrity worship and mental health. British Journal of Psychology, 95, 411-428.

Maltby, J., Day, L., McCutcheon, L. E., Martin, M. M. \& Cayanus, J. L. (2004). Celebrity worship, cognitive flexibility, and social complexity. Personality and Individual Differences, 37, 1475-1482. doi: 10.1016/j.paid.2004.02.004

Maltby, J., Giles, D. C., Barber, L., \& McCutcheon, L. E. (2005). Intense-personal celebrity worship and body image: Evidence of a link among female adolescents. British Journal of Health Psychology, 10(1), 17-32. Maltby, J., Houran, J., \& McCutcheon, L.E. (2003). A clinical interpretation of attitudes and behaviors associated with celebrity worship. The Journal of Nervous and Mental Disease, 191(1), 25-29. doi:

10.1097/01.NMD.0000044442.62137.59 
Maltby, J., Houran, J., Lange, R., Ashe, D., \& McCutcheon, L.E. (2002). Thou shalt worship no other gods unless they are celebrities: the relationship between celebrity worship and religious orientation. Personality and Individual Differences, 32(7), 1157-1172. doi: 10.1016/S0191-8869(01)00059-9

Maltby, J., McCutceon, L.E., Ashe, D.D., \& Houran, J. (2001). The self-reported psychological well-being of celebrity worshippers. North American Journal of Psychology, 3(3), 441-452.

Marwick, A. \& Boyd, D. (2011). To see and be seen: celebrity practice on Twitter. Convergence: The International Journal of Research into New Media Technologies, 17(2), 139-158.

McCutcheon, L. E. (2002). Machiavellianism, belief in a just world, and the tendency to worship celebrities. Current Research in Social Psychology, 8(9).

McCutcheon, L. E., Aruguete, M., Scott Jr., V. B., \& Von Waldner, K. L. (2004). Preference for solitude and attitude toward one's favorite celebrity. North American Journal Of Psychology, 6(3), 499-506.

McCutcheon, L. E., Ashe, D. D., Houran, J., \& Maltby, J. (2003). A cognitive profile of individuals who tend to worship celebrities. The Journal of Psychology, 137, 309-322.

McCutcheon, L.E., Lange, R., \& Houran , J. (2002). Conceptualize and measurement of celebrity worship. British Journal of Psychology, 93, 67-87.

McCutcheon L.E., \& Maltby J. (2002), Personality attributions about individuals high and low in the tendency to worship celebrities. Current Research in Social Psychology, (7), 325-338.

Moustakas, C. (1994). Phenomenological research methods. London, England: Sage.

North, A. C. \& Sheridan, L. P. (2009). Death, attractiveness, moral conduct, and attitudes to public figures. OMEGA--Journal of Death and Dying (Impact Factor: 0.44), 60(4), 351-363. doi: 10.2190/OM.60.4.c

North, A. C., \& Hargreaves, D. J. (2006). Problem music and self-harming. Suicide and Life-Threatening Behavior, $36,582-590$

North, A. C., Sheridan, L., Maltby, J., \& Gillett, R. (2007). Attribution style, self esteem, and celebrity worship. Media Psychology, 9, 291-308.

Park, A. (2008, September 15). Celebrity worship: good for your health?. Time: Health \& Family. Retrieved from http://www.time.com/time/health/article/0,8599,1841093,00.html

Rojek, C. (2012). Fame attack: The inflation of celebrity and its consequences. New York, NY: Bloomsbury Publishing Plc. 
Rubin, A. M., Perse, E., \& Powell, R. A. (1985). Loneliness, parasocial interaction, and local television news viewing. Human Communication Research, 12, 155-180.

Sheridan, L., Malbty, J. \& Gillett, R. (2006). Pathological public figure preoccupation: Its relationship with dissociation and absorption. Personality and Individual Differences, 41, 525-535. doi:10.1016/j.paid.2006.02.010

Sheridan, L., North, A., Maltby, J., \& Gillett, R. (2007). Celebrity worship, addiction and criminality. Psychology, Crime \& Law, 13(6), 559-571. doi: 10.1080/10683160601160653

Sansone, R.A, \& Sansone, L.A. (2014). I'm your number one fan -A clinical look at celebrity worship. Innovations in Clinical Neuroscience 11(1-2), 39-43.

Swami, V., Chamorro-Premuzic, T., Mastor, K. Siran, F.H., et al. (2010). Celebrity worship among university students in Malaysia: a methodological contribution to a celebrity attitude scale. European Psychologist. doi: $10.1027 / 1016-9040 / \mathrm{a} 000029$

The risks and potentials of celebrity marketing in Malaysia. (2011). Retrieved from http://www.marketingmagazine.com.my/breaking-news/the-risks-and-potentials-of-celebrity-marketing-inmalaysia

Thompson, J. (2009, July 1). Michael Jackson death has caused 'fans to committ suicide' as Rev Jesse Jackson urges them not to kill themselves. Mirror. Retrieved from http://www.mirror.co.uk/3am/celebrity-news/michaeljackson-death-has-caused-fans-403750

Urberg, K. A., Degirmencioglu, S. M., \& Pilgrim, C. (1997). Close friend and group influence on adolescent cigarette smoking and alcohol use. Developmental Psychology, 33, 834-844.

Wang, V. (2007, March 29). Father kills himself chiding Andy Lau's indifference to his daughter. China Daily. Retrieved from http://www.chinadaily.com.cn/entertainment/2007-03/29/content_839726.htm

Weinstein, D. \& Weinstein, M. (2003). Celebrity worship as weak religion. Word \& World, 25(3), $294-302$.

Yano, C. (1997). Charisma's realm: Fandom in Japan. Ethnology, 36(4), 335.

Yue, X. D. \& Cheung, C. (2013). Identity achievement and idol worship among teenagers in Hong Kong. International Journal of Adolescence and Youth, 11, 1-26. doi:10.1080/02673843.2003.9747914 
Current Psychology, 2016 pp. 1-10.

ACCEPTED: CELEBRITY WORSHIP

Yue, X. D. \& Cheung, C. (2000). Selection of favourite idols and models among Chinese young people: A comparative study in Hong Kong and Nanjing. International Journal of Behavioral Development, 24, 9198. 